\title{
Energy and Thermal Conductivity Assessment of Dimethyl-Ether and its Azeotropic Mixtures as Alternative Low Global Warming Potential Refrigerants in a Refrigeration System
}

\author{
Bukola Olalekan BOLAJI ${ }^{1 *}$, Olatunde Ajani OYELARAN ${ }^{2}$, Israel Olutunji ABIALA ${ }^{3}$, \\ Tunde Oluwatoyin OGUNDANA ${ }^{4}$, Semiu Taiwo AMOSUN ${ }^{5}$ \\ 1,2, ${ }^{4}$ Department of Mechanical Engineering, Faculty of Engineering, Ikole-Ekiti Campus, Federal \\ University Oye-Ekiti, PMB. 373, Ekiti State, Nigeria \\ ${ }^{3}$ Department of Mathematics, University of Lagos, Akoka, Lagos, Nigeria \\ ${ }^{5}$ Department of Mechanical and Mechatronic Engineering, Federal University, Otuoke, \\ Bayelsa State, Nigeria
}

\begin{abstract}
Substituting Hydrofluorocarbons with natural refrigerants in domestic refrigerators will significantly reduce the direct contributions of fluorinated gases to global warming which will be of great environmental benefit. In this study, the performances of dimethyl-ether (RE170) and its azeotropic mixtures (R510A and R511A) in a refrigeration system were assessed theoretically and compare with that of conventional refrigerant. The study revealed that the three investigated alternative refrigerants exhibited significantly good heat transfer characteristics, low pressure ratio, high latent heat in the liquid phase which resulted in their high thermal conductivity and Volumetric Cooling Capacity (VCC). The thermal conductivity of the refrigerants reduces while the evaporating temperature rises and the value obtained for RE170 was the highest among the four refrigerants studied. The Coefficient of Performance (COP) for RE170, R510A and R511A were higher than that of R134a by $6.20,10.06$ and $3.02 \%$ respectively while their power consumptions per ton of refrigeration were lower than that of R134a by $6.99,11.04$ and $1.47 \%$ respectively. In conclusion, dimethyl-ether and its azeotropic mixtures performed better than R134a in that they have higher thermal conductivity, refrigerating effect, VCC, COP, lower power consumption per ton of refrigeration and hence, they can be considered as suitable replacements for $\mathrm{R} 134 \mathrm{a}$ in domestic refrigerator.
\end{abstract}

Keywords - Azeotropic mixtures; alternative refrigerants; dimethyl-ether; domestic refrigerator; low global warming; $\mathbf{R 5 1 0 A}$ and $\mathbf{R 5 1 1 A}$; thermal conductivity

\begin{tabular}{ll} 
Nomenclature & \\
B & Constant in the linear expression for thermal conductivity $\left(\mathrm{W} / \mathrm{mK}^{2}\right)$ \\
CFC & Chlorofluorocarbon \\
COP & Coefficient of performance \\
DME or RE170 & Dimethyl-ether \\
GHG & Greenhouse gas \\
\hline
\end{tabular}

* Corresponding author.

E-mail address: bukola.bolaji@fuoye.edu.ng 


\begin{tabular}{|c|c|}
\hline$G W P$ & Global warming potential \\
\hline$h_{1}$ & Specific enthalpy of the gaseous refrigerant at the evaporator outlet $(\mathrm{kJ} / \mathrm{kg})$ \\
\hline$h_{2}$ & Specific enthalpy of gaseous refrigerant at outlet of the compressor $(\mathrm{kJ} / \mathrm{kg})$ \\
\hline$h_{3}$ & Specific enthalpy of the liquid refrigerant at the condenser outlet $(\mathrm{kJ} / \mathrm{kg})$ \\
\hline$h_{4}$ & Specific enthalpy of the liquid refrigerant at the evaporator inlet $(\mathrm{kJ} / \mathrm{kg})$ \\
\hline $\mathrm{HCFC}$ & Hydro-chlorofluorocarbon \\
\hline HFC & Hydrofluorocarbon \\
\hline$O D P$ & Ozone Depletion Potential \\
\hline$P_{\text {cond }}$ & Condensing pressure $\left(\mathrm{MN} / \mathrm{m}^{2}\right)$ \\
\hline$P_{\text {evap }}$ & Evaporating pressure $\left(\mathrm{MN} / \mathrm{m}^{2}\right)$ \\
\hline PFC & Perfluorocarbon \\
\hline PPTR & Power per ton of refrigeration \\
\hline$P R$ & Pressure ratio \\
\hline$Q_{\text {cond }}$ & Condenser heat load $(\mathrm{kJ} / \mathrm{kg})$ \\
\hline$Q_{\text {evap }}$ & Refrigerating effect (kJ/kg) \\
\hline $\mathrm{R} 12$ & Dichlorodifluoromethane \\
\hline R134a & $1,1,1,2$-Tetrafluoroethane \\
\hline R290 & Propane \\
\hline R510A & Binary mixture of $88 \%$ RE 170 and $12 \%$ R600a by mass \\
\hline R511A & Binary mixture of $95 \%$ R 290 and $5 \%$ RE 170 by mass \\
\hline R600a & Isobutane \\
\hline $\mathrm{SF}_{6}$ & Sulphur hexafluoride \\
\hline $\mathrm{T}$ & Absolute temperature $(\mathrm{K})$ \\
\hline$V C C$ & Volumetric cooling capacity \\
\hline VCRS & Vapour compression refrigerating system \\
\hline$W_{\text {comp }}$ & Compressor work input \\
\hline$\lambda$ & Thermal conductivity (W/mK) \\
\hline$\lambda_{\mathrm{b}}$ & The thermal conductivity at the normal boiling point (W/mK) \\
\hline
\end{tabular}

\section{INTRODUCTION}

Refrigeration or artificial production of cold has a great impact on the modern society. In addition to the provision of good and comfortable living environments, it is also considered as necessity for surviving harsh weather. Refrigeration applications provide comfort for workers, increase their productivity and make many vital production processes possible. It enables: production and storage of pharmaceutical materials and medical facilities, food preservation, transportation and storage [1]-[3]. It also prevents spreading of diseases. Refrigeration is a process of moving heat from the low temperature reservoir (space to be cooled) and subsequently rejecting that heat into high temperature reservoir. Mechanical work is the conventional method of transferring heat, but heat can also be transferred by other means such as: electricity, magnetism and laser. However, the most common method of 
refrigeration and air conditioning applications all over the world is mechanical based vapour compression refrigeration [4]-[6].

Refrigerant is the working medium used in vapour compression refrigerating systems (VCRSs) which evaporates by taking the heat of vaporization from the refrigerating chamber, consequently reducing the temperature of the chamber. The design of the VCRS is highly dependent on the refrigerant in the system and since the invention various volatile chemicals or refrigerants have been developed throughout the history of the refrigeration industry with different aims, such as stability, safety, durability and reliability [7]. All through the major part of the 20th century, halogenated hydrocarbons (especially hydro-chlorofluorocarbons (HCFCs) and chlorofluorocarbons (CFCs) were the dominant refrigerants for refrigeration and air-conditioning system due to their outstanding physical, thermodynamic and safety properties which made them preferable than the toxic and inefficient first-generation refrigerants for example ammonia, sulphur and carbon dioxide [8], [9]

However, these chlorine containing chemicals (CFCs and HCFCs), despite their excellent stability, safety and thermophysical properties, have contributed greatly to the global environmental problem of stratospheric ozone depletion. The chlorine content of the chemicals is the main cause; it reacts catalytically with ozone in the destruction process without itself undergoing any permanent changes. The relative quantity of the ozone destroyed per kilogram of a chemical, relative to the standard CFC refrigerant, is referred to as Ozone Depletion Potential (ODP) which is the ability of a chemical to destroy ozone layer. $\mathrm{R} 11$ is the standard or reference refrigerant for ozone depletion and it is assigned ODP of one [5], [10].

In accordance with the Montreal Protocol, CFCs were banned in the advanced countries on January 1, 1996 and on January 1, 2010 in the other part of the world [11]-[13]. Similarly, in agreement to the Copenhagen amendments to the Montreal Protocol, the partial halogenated refrigerants (HCFCs), despite their significantly low ODP were initially scheduled for global phase-out by 2040 but their phase-out schedule has been accelerated and fixed for 2030 [14], [15]. European countries have phase-out HCFCs in 2014 which is much earlier than the stipulation of Montreal Protocol [16], [17]. Table 1 shows the environmental indicators of some halogenated refrigerants.

TABLE 1. ENVIRONMENTAL INDICATORS OF SOME HALOGENATED REFRIGERANTS [15], [18]

\begin{tabular}{llll}
\hline Halogen source gas & Atmospheric lifetime (years) & ODP & GWP \\
\hline $\mathrm{CCl}_{3} \mathrm{~F}$ or R11 & 45.0 & 1.000 & 4750 \\
$\mathrm{CCl}_{2} \mathrm{~F}_{2}$ or R12 & 100.0 & 0.820 & 10900 \\
$\mathrm{C}_{2} \mathrm{Cl}_{3} \mathrm{~F}_{3}$ or R113 & 85.0 & 0.850 & 6130 \\
$\mathrm{CCl}_{4}$ or R10 & 26.0 & 0.820 & 1400 \\
$\mathrm{CHClF}_{2}$ or R22 & 12.0 & 0.050 & 1810 \\
$\mathrm{C}_{2} \mathrm{HCl}_{2} \mathrm{~F}_{3}$ or R123 & 1.3 & 0.020 & 77 \\
$\mathrm{C}_{2} \mathrm{HClF}_{4}$ or R124 & 5.8 & 0.022 & 609 \\
$\mathrm{C}_{2} \mathrm{H}_{3} \mathrm{Cl}_{3}$ or R140 & 5.0 & 0.160 & 146 \\
$\mathrm{CBrF}_{3}$ or Halon-1301 & 65.0 & 15.900 & 7140 \\
$\mathrm{CClBrF}_{2}$ or Halon-1211 & 16.0 & 7.900 & 1890 \\
$\mathrm{CH}_{3} \mathrm{Br}$ or Methyl bromide & 0.8 & 0.660 & 5 \\
\hline $\mathrm{ODP}_{2} \mathrm{Oz}$.
\end{tabular}

ODP: Ozone depleting potential; GWP: Global warming potential

Since the prohibition of CFCs and HCFCs, refrigeration industry has adopted hydrofluorocarbons (HFCs) refrigerants and their mixtures such as R32, R23, R134a, R413A, 
R404A, R407C, R410A and R429A as alternatives which are still widely used today [19], [20]. The most prominent among them is R134a. The use of HFC refrigerants has grown significantly since their introduction as replacements for HCFC and CFC. They are now the most commonly used refrigerants in domestic refrigerators and other refrigeration systems [21].

Global warming has turn out to be another most important environmental issue subsequent to the ozone layer depletion. The world has recorded about $0.8{ }^{\circ} \mathrm{C}$ rise in global mean temperatures over the past century and scientists agreed that this global rise temperature is principally caused by human activity which has taken place from the time of the industrial revolution [12], [15]. This resulted in the Kyoto Protocol which sets out to control the emissions of the Green House Gases (GHGs) which include "F-gases" such as HFCs, PFCs and SF6 which are normally referred to as "fluorinated greenhouse gases". Other GHGs are $\mathrm{CH}_{4}, \mathrm{CO}_{2}$ and $\mathrm{N}_{2} \mathrm{O}$. HFCs are synthetic refrigerants just like the CFCs and HCFCs they have replaced; hence they are foreign to the environment. Although these refrigerants have zero ODP because they are entirely friendly to ozone layer and have played a significant role in the phase-out of chlorinated refrigerants (HCFCs and CFCs), most of them also pose another environmental issue by their contribution to global warming [22].

Global Warming Potential (GWP) represents the atmospheric lifetime of a gas and the quantity of the infrared radiation it can absorb over a period of 100 years relative to $\mathrm{CO}_{2}$ which is assigned a GWP of 1.0. Chemicals with very short (a few days) atmospheric lifetimes have insignificant GWPs [23]. Under Kyoto protocol, HFC refrigerants that are once considered as environment-friendly alternatives are now one of the six greenhouse gases and they are already been scheduled for phase-out [24], [25]. The projected commitment to decrease HFC refrigerants consumption in the last few years has motivated interest in the natural refrigerants which have good thermophysical properties and low GWP.

The group of naturally occurring substances (ammonia, carbon dioxide, air, water and hydrocarbons) that are normally utilized in refrigeration and air-conditioning systems are referred to as natural refrigerants. Hydrocarbons, in this collection, are the chemicals that have close relationship with HFCs with similar transport and thermodynamic properties. For this reason, they are very suitable as retrofitting refrigerants without any major change in the design of the existing HFC and HCFC systems [26]-[28]. Hydrocarbons are part of the firstgeneration refrigerants and they were the main commonly used refrigerants in the refrigeration systems before the discovery of CFC and HCFC in the 1930s.

The current attention given to hydrocarbons as working fluids in industrial, commercial and domestic refrigerators in the past two decades is as a result of the emerging of the two serious global environmental problems in which hydrocarbons does not have any negative involvement. Besides having zero ODP and significantly low GWP, hydrocarbons are nontoxic, well-matched with various oils utilized in the refrigeration equipment, readily available and cheap [29]. It has been reported that the quantity of charge required by the refrigeration equipment utilizing $\mathrm{CFC}$ refrigerants is twice the amount required using hydrocarbons for the same refrigerating capacity [30].

One of the hydrocarbon refrigerants that has excellent thermophysical and environmental properties is dimethyl-ether (DME, RE170). RE170 is readily available, compatible with mineral oils and also suitable for being used with ferrous metals, copper, copper-based alloys and aluminium [31], [32]. The ODP of dimethyl-ether is equal to zero and as a result of its short atmospheric lifetime (6 days), its GWP is significantly very low which have made it a potential green refrigerant to the environment. This refrigerant and its mixtures are good alternatives to the conventional HFC refrigerant in domestic refrigerator (R134a). The ODP of R134a is zero, but it has a relatively high GWP of 1430 [21], [33]. Since January 1, 2017 
European countries have made illegal the use of refrigerants with global warming potential above 150 in the domestic refrigeration and mobile air-conditioning systems [34]. Other hydrocarbon refrigerants that are potential alternatives to $\mathrm{R} 134 \mathrm{a}$ in domestic refrigerator are propane (R290) and isobutane (R600a).

Propane has been proposed as a retrofitting refrigerant for existing R12 systems because its physical properties are thermodynamically equivalent to those of R12 and even superior in some aspects. R290 has no ODP and negligible global warming potential (less than 4.0). Its refrigeration effect per $\mathrm{kg}$ is more than twice that of $\mathrm{R} 12$, hence the mass charge of refrigerant required in a propane system is only half of that of R12 system [35], [36]. Isobutane (R600a) is also a possible replacement for the environmental unfriendly refrigerants (R12, R22 and R134a) in domestic refrigerators. R600a and its mixtures have zero ODP, very low global warming potential and they are readily available all over the world because they formed part of the petroleum gases from natural sources [37]. R600a has been in use in refrigerator in the past up to the 1940s and now, the new interest in the fluid commenced in 1993 when Greenpeace presented the Green freeze project with the German company Foron [38].

So far as hydrocarbons refrigerant is concerned, flammability is the only important challenge as regards their widely acceptance. However, it is a common knowledge that vast quantities of hydrocarbons are employed annually worldwide (without any harm) for powering vehicles, as aerosol propellants and as a source of energy for domestic activities such as heating and cooking [39]. Hydrocarbon Refrigerants do not unexpectedly burst into flames when it escapes from the system in to the air. The following fundamental incidences must happen together before the occurrence of any combustion: hydrocarbon must be released, mixed with the accurate amount of air and the ignition source greater than $440{ }^{\circ} \mathrm{C}$ needs be present. If one of these three elements is eliminated, combustion cannot occur [40].

Various measures and standards have been considered and implemented by the refrigeration industry to guarantee the safe use of the hydrocarbon products. Some of the applications and new development put in place in managing the problems of flammability and safety are: the use of new designed heat exchangers of better compactness, complete system optimization and designs, reduction in the system refrigerant mass charge and the establishment of safety precautions in terms of the rules and regulations. The modem systems are so well built that the possibility of leakage is virtually non-existent [25].

In this study, the performance of dimethyl-ether (RE170) and its azeotropic mixtures (R510A and R511A in terms of their thermal conductivity and cooling capacity in a refrigeration system were assessed theoretically and compare with that of baseline refrigerant (R134a). Azeotropic refrigerant mixtures contain two or more refrigerants but behave like pure refrigerants which condense and evaporate at constant temperature and pressure [32], [41]. They have the advantage of constant composition upon evaporation or condensation consequently there will be no separation during these two heat exchanging processes in refrigeration system. Azeotropic mixtures produce lower boiling point which means lower evaporating temperatures and higher capacity [42]. Table 2 shows some important physical and environmental properties of the studied hydrocarbon refrigerants. 
TABle 2. PhysicAl AND ENVIRONMENTAL Properties of the Studied Hydrocarbon REFRIGERANTS [18], [43]

\begin{tabular}{|c|c|c|c|c|}
\hline \multirow[t]{2}{*}{ Properties } & \multicolumn{4}{|c|}{ Refrigerants } \\
\hline & $\mathrm{R} 134 \mathrm{a}$ & RE170 & R510A & R511A \\
\hline Normal boiling point temperature, ${ }^{\circ} \mathrm{C}$ & -26.07 & -24.78 & -25.20 & -42.10 \\
\hline Critical point temperature, ${ }^{\circ} \mathrm{C}$ & 101.06 & 127.23 & 125.67 & 96.98 \\
\hline Critical point pressure, $\mathrm{MPa}$ & 4.06 & 5.34 & 5.12 & 4.29 \\
\hline Liquid phase density, $\mathrm{kg} / \mathrm{m}^{3}$ at $25^{\circ} \mathrm{C}$ & 1206.70 & 661.43 & 649.05 & 498.48 \\
\hline Vapour phase density, $\mathrm{kg} / \mathrm{m}^{3}$ at $25^{\circ} \mathrm{C}$ & 32.35 & 12.44 & 12.71 & 20.68 \\
\hline Molar mass, $\mathrm{kg} / \mathrm{kmol}$ & 102.03 & 46.07 & 47.24 & 44.19 \\
\hline Latent heat at $-15^{\circ} \mathrm{C}, \mathrm{kJ} / \mathrm{kg}$ & 209.49 & 453.67 & 443.39 & 397.60 \\
\hline Ozone Depletion Potential, $O D P$ & 0 & 0 & 0 & 0 \\
\hline Global Warming Potential, GWP & 1430 & 1 & 2 & 4 \\
\hline
\end{tabular}

\section{Materials ANd Methods}

\subsection{Refrigeration cycle analysis}

Most of the modern refrigeration systems such as air-conditioning and heat pump are built based on the principle of mechanical refrigeration system. The refrigeration system employs various refrigerants depending whether it is for small or large unit, low, medium or high temperature application. The refrigerant operates in a closed cycle and flows round through a sequence of processes to absorb heat from a low-temperature reservoir known as refrigerating chamber or evaporator and rejects the heat in the condenser at high temperature in manner that the ending state of the refrigerant is one and the same in all respects to its initial state. Fig. 1 shows the schematic drawing and components layout of the refrigeration system. The figure clearly shows the most important components; a compressor, an expansion device (capillary tube), an evaporator and a condenser. The last two on the list are the two heat exchangers where the heat is added and rejected from the refrigerant respectively.

The compressor works by drawing saturated refrigerant of low temperature vapour from evaporator (the system's low pressure side) and conveying refrigerant of high pressure vapour to the condenser (high pressure side). In the condenser, the gaseous refrigerant of high temperature and pressure loses its latent heat to the air either by natural or force circulation and consequently, condenses into liquid at constant temperature and pressure. This liquid refrigerant flows to the expansion or throttling device (in this case, capillary tube) which reduces the pressure and consequently the temperature to that in the cooling chamber coil (evaporator). Finally, the heat of vaporization is supplied to the liquid refrigerant by the medium being cooled through the coil walls to boil and change its phase back to vapour refrigerant. 


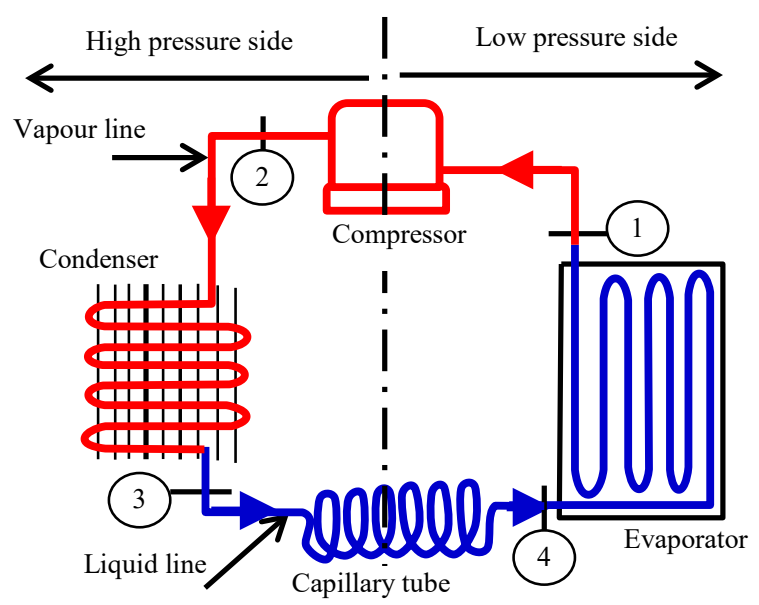

Fig. 1. Schematic illustration and components layout of the refrigeration system. 1: Evaporator outlet; 2: Compressor outlet; 3: Condenser outlet; 4: Capillary tube outlet.

\subsection{Energy and heat transfer analysis of the refrigeration system}

Heat transferred from the medium being cooled in the evaporating chamber to the refrigerant is known as refrigerating effect. With reference to Fig. 2 and assuming heat losses in the pipe lines between components to be negligible, the heat transfer and the work done in the system can be analysed as follow:

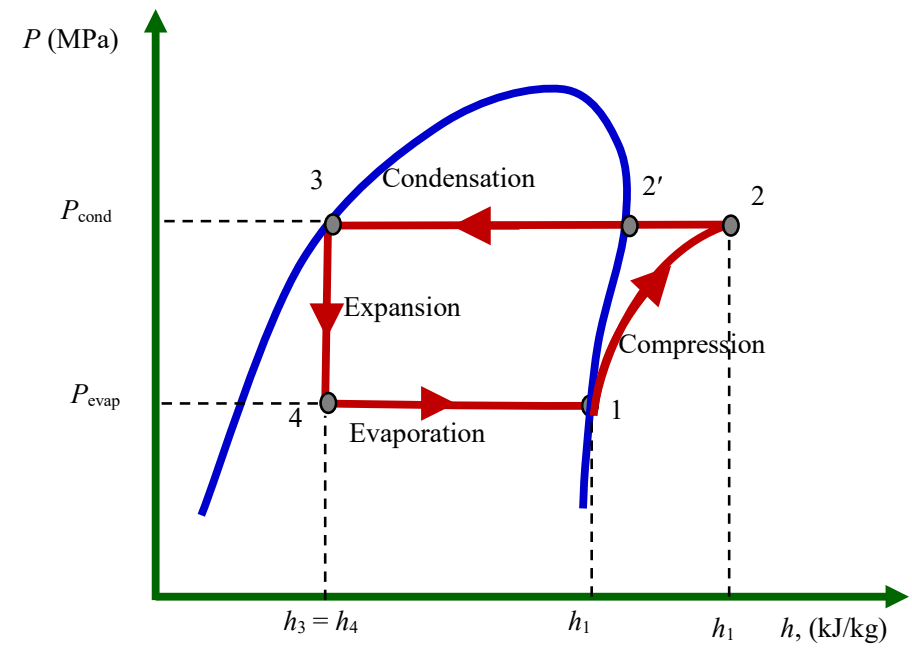

Fig. 2. Vapour compression refrigeration cycle on $p$ - $h$ diagram. 1: Evaporator outlet; 2: Compressor outlet; 3: Condenser outlet; 4: Capillary tube outlet.

a) Heat transfer in the Condenser: The condenser heat load $\left(Q_{\text {cond }}, \mathrm{kJ} / \mathrm{kg}\right)$ is the difference in the specific enthalpy of the gaseous refrigerant going out of the compressor or coming into the condenser $\left(h_{2}, \mathrm{~kJ} / \mathrm{kg}\right)$ and the specific enthalpy of the liquid refrigerant going out into the condenser $\left(h_{3}, \mathrm{~kJ} / \mathrm{kg}\right)$ : 


$$
Q_{\text {cond }}=\left(h_{2}-h_{3}\right)
$$

b) Compressor work input: The work input ( $\left.W_{\text {comp }}\right)$ is calculated as the difference in the specific enthalpy of gaseous refrigerant going out of the compressor $\left(h_{2}, \mathrm{~kJ} / \mathrm{kg}\right)$ and specific enthalpy of the gaseous refrigerant going out of the evaporator or coming into the compressor $\left(h_{1}, \mathrm{~kJ} / \mathrm{kg}\right)$ :

$$
W_{\text {comp }}=\left(h_{2}-h_{1}\right)
$$

c) Heat transfer in the evaporator: The heat absorbed by the refrigerant in the evaporator or refrigerating effect $\left(Q_{\text {evap }}, \mathrm{kJ} / \mathrm{kg}\right)$ is computed as the difference in the specific enthalpy of the liquid refrigerant coming into the evaporator $\left(h_{4}, \mathrm{~kJ} / \mathrm{kg}\right)$ and specific enthalpy of the vapour refrigerant going out of the evaporator $\left(h_{1}, \mathrm{~kJ} / \mathrm{kg}\right)$ :

$$
Q_{\text {evap }}=\left(h_{1}-h_{4}\right)
$$

d) The efficiency of the system is determine using the term COP (coefficient of performance) and is calculated as the ratio of refrigerating effect to the work input through the compressor. Equation 4 shows that reduction in energy consumption will increase the $C O P$ of the system:

$$
C O P=\frac{Q_{\text {evap }}}{W_{\text {comp }}}
$$

e) The heat loss in the throttling or expansion device (capillary tube) is negligible and hence, the process from point 3 to 4 as shown in Fig. 2, occurred at constant enthalpy (isenthalpy):

$$
h_{3}=h_{4}
$$

f) The ratio of the absolute condensing pressure $\left(P_{\text {cond }}, \mathrm{MN} / \mathrm{m}^{2}\right)$ to the absolute evaporating pressure $\left(P_{\text {evap }}, \mathrm{MN} / \mathrm{m}^{2}\right)$ is computed as follows:

$$
P R=\frac{P_{\text {cond }}}{P_{\text {evap }}},
$$

where PR is the system pressure ratio and it is dimensionless.

g) The system's useful indicator for energy performance is the PPTR (power per ton of refrigeration) and is calculated as follow [41]:

$$
P P T R=\frac{3.5 W_{\text {comp }}}{Q_{\text {evap }}}
$$

h) The product of the density $\left(\rho_{1}, \mathrm{~kg} / \mathrm{m}^{3}\right)$ of refrigerant at the suction to the compressor and the refrigerating effect $\left(Q_{\text {evap }}, \mathrm{kJ} / \mathrm{kg}\right)$ is known as volumetric cooling capacity $\left(V C C, \mathrm{~kJ} / \mathrm{m}^{3}\right)$. It is expressed as [43]:

$$
V C C=\rho_{1} \cdot Q_{\text {evap }}
$$

\subsection{Thermal conductivity of the investigated refrigerants}

The variation of thermal conductivity with respect to the thermodynamic state of liquid refrigerants is of engineering importance. The thermal conductivity of most liquids refrigerants have been established to be in the range of $0.100-0.200 \mathrm{~W} / \mathrm{mK}$ except for some 
liquid such as water and ammonia. Also, the values for the refrigerants in liquid state have been established to be in the ranges of 10-100 times the values in their gaseous state [44], [45]. Thermal conductivity of most liquid refrigerant generally reduces with increase in temperature, and under normal boiling point, the thermal conductivity $(\lambda, \mathrm{W} / \mathrm{mK})$ is usually linear and can be represented as [44].

$$
\lambda=\lambda_{\mathrm{b}}-\mathrm{BT},
$$

where $\lambda_{b}$ represents the thermal conductivity at the normal boiling point $(\mathrm{W} / \mathrm{mK})$; B is function of temperature and is the constant in the linear expression for thermal conductivity $\left(\mathrm{W} / \mathrm{mK}^{2}\right)$; and $\mathrm{T}$ is the absolute temperature $(\mathrm{K})$.

\subsection{Thermodynamic properties analysis of the investigated refrigerants}

The functional and essential parameters needed to assess the performance of the system's components working with a particular refrigerant are the transport properties of that refrigerant under various operating conditions while the physical properties of the refrigerant are needed to establish the applicability of the refrigerant under design working conditions. Hence, the most widely used refrigerant properties' database (REFPROP 9.1 software) was used for the computational analysis of the heat transfer in the four major components using a simple vapour compression refrigeration cycle. The software controls equations-of-state (EOS) for a broad variety of fluids and it is able to generate an extensive range of refrigerant properties for both pure and different blends. The limitations and the uncertainties have been stated in the software [34], [43]. The data obtained were used to assess the energy, thermal conductivity and other fundamental performance parameters of dimethyl-ether (RE170) and its azeotropic mixtures (R510A and R511A) and compare them with those of the conventional refrigerant in domestic refrigerator (R134a).

\subsection{Characteristics and chemical composition of the investigated refrigerants}

The conventional refrigerant, 1,1,1,2-Tetrafluoroethane (R134a) is from the compositional group of $\mathrm{HFC}$ with molecular formula CF3CH2F. R134a is an ozone friendly refrigerant with zero ODP and is the current widely used refrigerant in refrigeration and air conditioning systems. However, beside its relatively high GWP of 1430, studies have shown that it absorbed moisture during operations which make it susceptible to rusting and copper plating [7], [46]. Also, R134a like all other HFC refrigerants is not compatible and miscible with the traditional synthetic and mineral oils therefore, polyalkylene glycol (PAG) and polyol ester (POE) which are expensive, extremely hygroscopic in nature, result in irritation when in interact with skin and leads to some other service issues [47]. Consequently, it is obvious that natural refrigerants with good environmental and thermophysical properties are preferable in refrigeration systems.

R510A and R511A are azeotropic mixtures of natural refrigerants consist of dimethyl-ether (RE170), isobutane (R600a) and propane (R290) as components. RE170 or DME is an organic compound and an isomer of ethanol with a chemical formula of $\mathrm{C}_{2} \mathrm{H}_{6} \mathrm{O}$. It is also called methoxymethane. RE170 is a liquefied gas which is nontoxic, odourless and colourless at room temperature. The ozone depletion potential of dimethyl-ether is equal to zero and its global warming potential is significantly very low $(G W P=1)$ which have made it a potential green refrigerant to the environment [48].

Isobutane (R600a), also referred to as methylpropane, is an isomer of butane with molecular formula $\mathrm{HC}(\mathrm{CH} 3) 3$. It is a nontoxic, odourless and colourless gas. It has an excellent compatibility with several lubricants. In particular, it is an ozone friendly refrigerant with 
zero $O D P$ and it does not cause greenhouse effect due to its very low $G W P$ of 3 . The other component of the mixtures is propane (R290), an alkane with three-carbon (C3H8). It is a byproduct in the production of natural gas. It is also a nontoxic, odourless and colourless gas and it has excellent environmental and thermophysical properties $(O D P=0$ and $G W P=3)$. R510A is a binary mixture consists in mass ratio $88 \%$ of RE170 and $12 \%$ of R600a, while R511A is also a binary mixture consists $95 \%$ of R290 and $5 \%$ of RE170 by mass ratio [3]. Table 2 shows some important physical and environmental properties of the studied hydrocarbon refrigerants.

\subsection{Availability and cost analysis of the studied refrigerants}

RE170 is produced from a variety of resources such as natural gas, biomass coal and methanol. Other components of R510A and R511A are hydrocarbons gasses (R600a and $\mathrm{R} 290$ ) and they are natural refrigerants generated as by-products in the production of natural gas [48]. The retail price or cost of refrigerants differs, with RE170 and its mixtures apt tending to cost less than conventional refrigerant (R134a). The cost of R134a is in the range of 30 to $50 \mathrm{USD} / \mathrm{kg}$ while the cost of the hydrocarbon refrigerants (RE170, R600a and R290) is in the range of 0.3 to $6.0 \mathrm{USD} / \mathrm{kg}$. R510A and R511 A are binary blends of the hydrocarbon refrigerants [3], [48]. Therefore, the average cost of RE170, R510A and R511A is about $33.3 \%$ less than the cost of R134a.

\section{RESUlts AND DiscuSSION}

Fig. 3 shows the vapour pressure profiles of RE170 and its azeotropic mixtures compared with that of R134a. The curves for RE170 and R510A, as revealed in the figure, are close with slight deviations of about $5.95 \%$ and $6.60 \%$ to that of R134a between the temperature ranges of -30 to $40{ }^{\circ} \mathrm{C}$, while curve of $\mathrm{R} 511 \mathrm{~A}$ is $19.58 \%$ deviated from that of R134a between the same temperature ranges.

Fig. 4 shows the profiles of the pressure ratio at varying evaporating temperature for the studied working fluids. As revealed in the figure, the pressure ratios for all the four refrigerants reduce as the evaporating temperature rises. The pressure ratios of RE170, R510A and R511A are closely followed that of R134a with the improvement of lower deviations of $3.09,4.10$ and $14.81 \%$ respectively. All the three refrigerants are good alternatives due to their lower pressure ratios, but RE170 and R510A refrigerants are more suitable to use the same compressor with R134a, while R511A will require a slightly less bulky compressor for the same capacity. These results agree with the results obtained by Borokinni et al. [3]. 


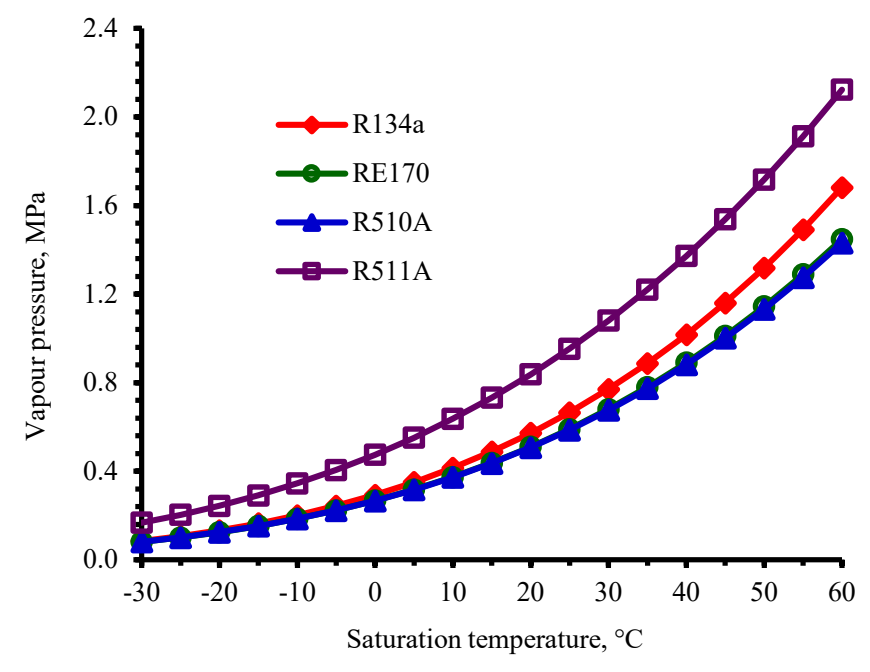

Fig. 3. Saturation vapour pressure curves.

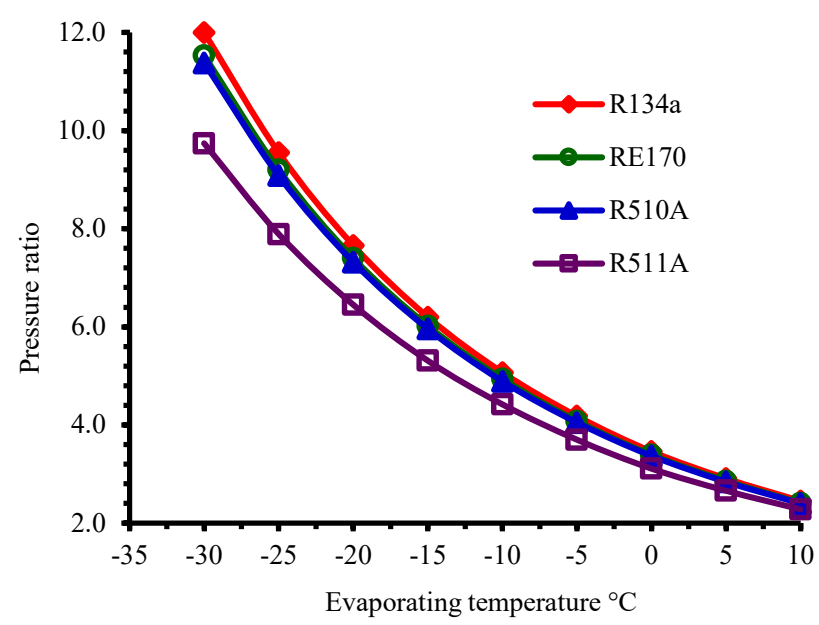

Fig. 4. Effect of the evaporating temperature on the system's pressure ratio.

Higher refrigerating capacity is the central goal of any refrigeration system. Fig. 5 shows the refrigerating effect versus evaporating temperature for RE170, R510A, R511A and $\mathrm{R} 134 \mathrm{a}$. As clearly revealed in the figure, increase in the evaporating temperature gradually increases the refrigerating effect. The refrigerating effects obtained for RE170 and its azeotropic refrigerant mixtures (R510A and R511A) were higher than that of the conventional refrigerant by $191.44,176.95$ and $120.98 \mathrm{~kJ} / \mathrm{kg}$, respectively. This is similar to the results obtained in the study of sub-cooling refrigeration system conducted by Opeyemi et al. [29] where higher refrigerating effects of 178.6 and $111.96 \mathrm{~kJ} / \mathrm{kg}$ than that of R134a were obtained for R510A and R600a respectively. This is as a result of their superior latent heat as shown on Table 2. High value of latent heat has positive effect of decreasing the required refrigerant 
flow rate which will increase the system's capacity and improve the efficiency. Dimethylether (RE170) achieved the highest refrigerating effect for the system.

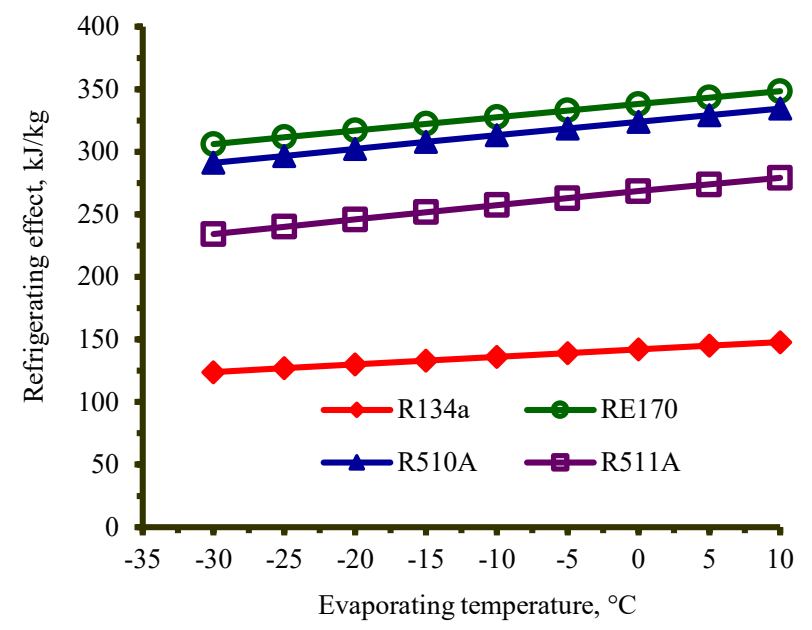

Fig. 5. Refrigerating effect versus evaporating temperature.

Fig. 6 shows curves of the Volumetric Cooling Capacity (VCC) for the four studied refrigerants at varying evaporating temperature. As shown in the figure, the VCCs for RE170 and its azeotropic refrigerants (R510A and R511A) increase as the evaporating temperature increases. Increase in the refrigerant's temperature in the evaporator, increases the volume of the vapour refrigerant at its exit which also enhances the cooling effect. The $V C C$ s for the three alternative working fluids are all higher than that of R134a. The azeotropic refrigerant (R511A) achieved the highest $V C C$ in the system. The average VCCs obtained for RE170, R510A and R511A between the evaporating temperature ranges of -30 to $10{ }^{\circ} \mathrm{C}$ were higher by $5.24 \%, 13.89 \%$ and $28.26 \%$ respectively, than that of conventional refrigerant, whereas in the study of R1234yf as an alternative to R134a, conducted by Navarro-Esbri et al. [24], the cooling capacity obtained for R1234yf was $9 \%$ lower than that of R134a.

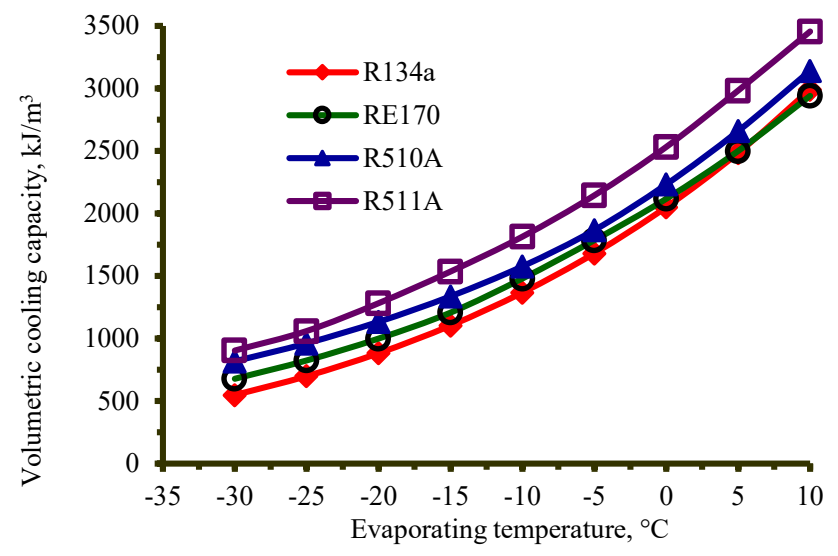

Fig. 6. Volumetric cooling capacity $(V C C)$ versus evaporating temperature. 
The thermal conductivity at varying evaporating temperature for RE170, R510A and R511A compare with that of R134a are illustrated in Fig. 7. The figure reveals that thermal conductivity decreases as evaporating temperature rises which is due to the fact that increase in evaporating temperature decreases the viscosity of refrigerant and viscosity is directly proportional to thermal conductivity. The thermal conductivities of dimethyl-ether and its azeotropic refrigerant mixtures are superior to that of conventional refrigerant (R134a). The average values obtained between the evaporating temperature ranges of -30 to $10{ }^{\circ} \mathrm{C}$ for RE170, R510A and R511A were 44.17, 40.17 and $16.36 \%$ respectively higher than that of R134a.

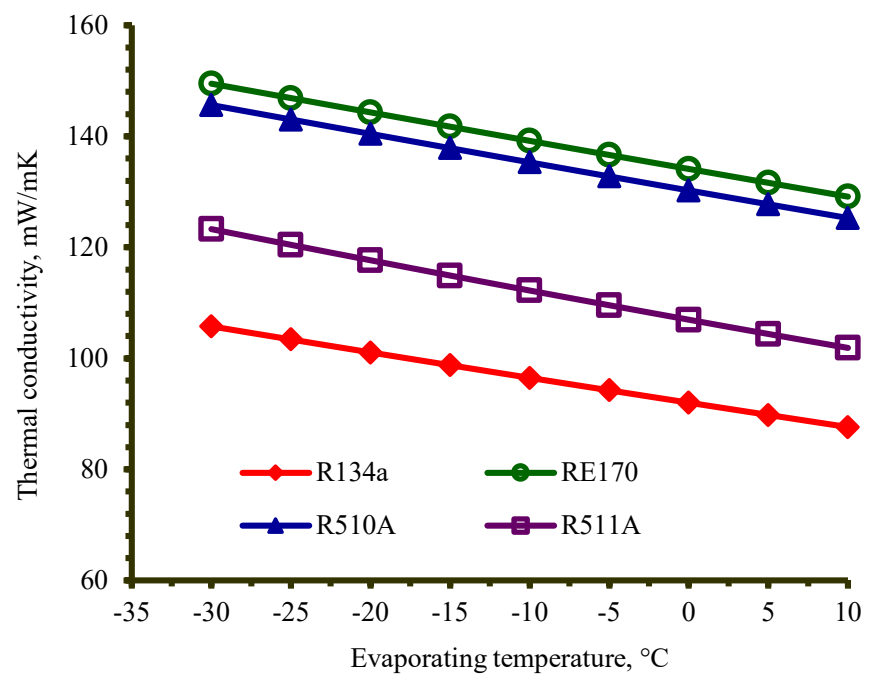

Fig. 7. Thermal conductivity versus evaporating temperature.

Fig. 8 shows the Coefficient of Performance (COP) for RE170, R510A, R511A and R134a at different evaporating temperatures. As the evaporating temperature increases the COP also increases. This is as a result of increase in the refrigerating effect (Fig. 5) which consequently increases the COP of the system (Eq. 5). Again, the COPs of RE170, R510A and R511A were higher by $6.20,10.06$ and $3.02 \%$ respectively above that of R134a. The variation of the power consumption per ton of refrigeration (PPTR) with the evaporating temperature for (RE170, R510A, R511A and R134a) is shown in Fig. 9. It can be deduced with reference to the figure that the PPTR decreases as the temperature in the evaporator coil rises for all the studied refrigerants. The results show that RE170 and its azeotropic mixtures exhibited lower energy utilization than the conventional refrigerant in the domestic refrigerator. R510A has emerged as the refrigerant that achieved the lowest PPTR followed by RE170 and R511A in that order. The average values for these three refrigerants are $11.04 \%, 6.99 \%$ and $1.47 \%$, respectively less than that of R134a. Banjo et al. [27] also reported $4.5 \%$ reduction in energy consumption when R134a system was retrofitted with R600a. 


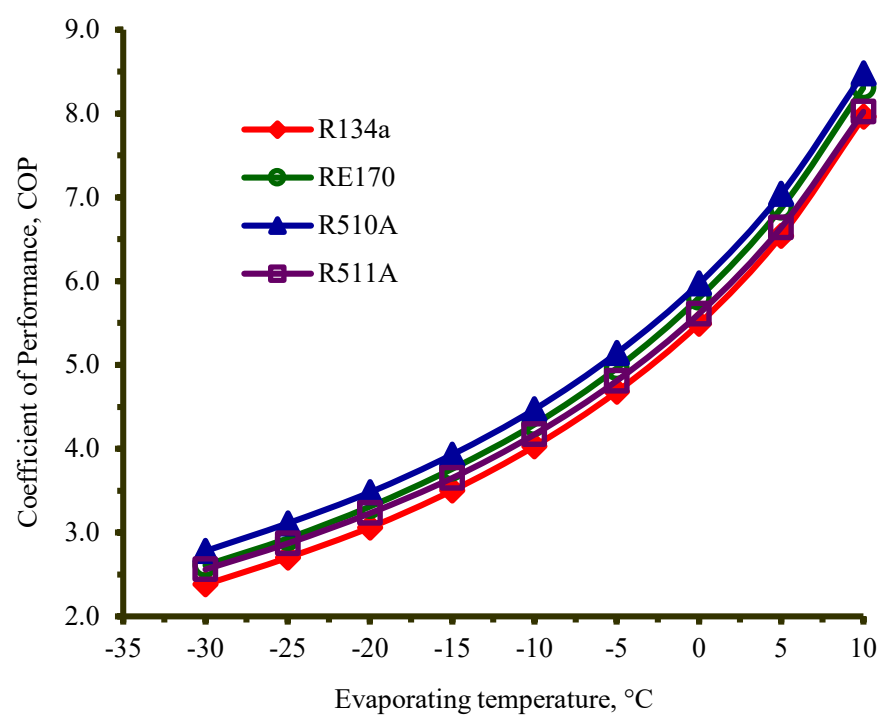

Fig. 8. Coefficient of Performance (COP) versus evaporating temperature.

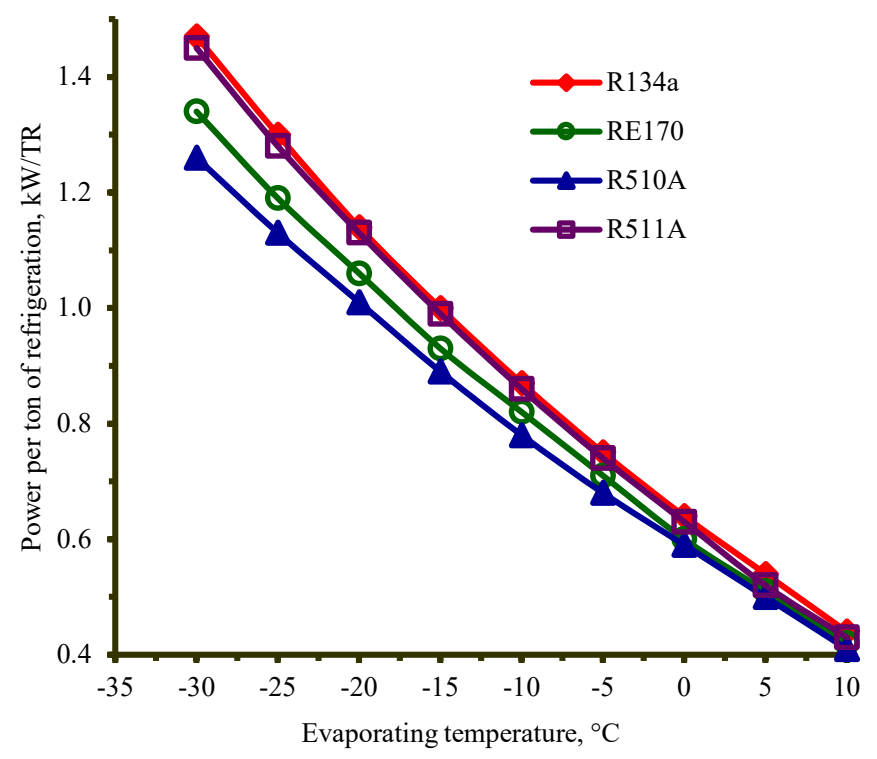

Fig. 9. Power per ton of refrigeration at different evaporating temperature.

\section{Conclusions}

RE170, R510A and R511A are natural refrigerants, environmentally friendly and they have excellent thermophysical properties. They are possible alternatives to the high global warming potential refrigerant currently used in domestic refrigerators. The performance of these eco-friendly refrigerants in terms of their energy, thermal conductivity, cooling capacity and other fundamental performance parameters in the refrigeration system were assessed 
theoretically and compare with that of conventional refrigerant (R134a). The followings are the conclusions with respect to the results obtained:

1. RE170 and R510A refrigerants showed very close saturation vapour pressure curves to that of R134a with improvement of slightly lower deviation.

2. The pressure ratios obtained for RE170, R510A and R511A were lower than that of R134a by $3.09,4.10$ and $14.81 \%$ respectively.

3. Dimethyl-ether (RE170) and its azeotropic refrigerant mixtures (R510A and R511A) exhibited very high refrigerating effect in comparison with that of R134a. This is as a result of their very high latent heat in the liquid phase.

4. The average VCCs obtained for RE170, R510A and R511A between the evaporating temperature ranges of $-30{ }^{\circ} \mathrm{C}$ to $10{ }^{\circ} \mathrm{C}$ were $5.24 \%, 13.89$ and $28.26 \%$ respectively higher in comparison with that of R134a.

5. The thermal conductivities of dimethyl-ether and its azeotropic refrigerant mixtures are superior to that of conventional refrigerant with highest value achieved using dimethylether (RE170) in the system

6. Highest $C O P$ in system was attained using R510A, an azeotropic refrigerant blend. In comparison with the baseline refrigerant, the use of RE170, R510A and R511A has increased the system's COP by $6.20 \%, 10.06 \%$ and $3.02 \%$ respectively.

7. RE170, R510A and R511A are energy efficient refrigerants in that their energy consumptions were lower than that of conventional refrigerant in the domestic refrigerator. R510A has emerged as the refrigerant that achieved the lowest specific energy consumption among the studied refrigerants.

Generally, the study has revealed the superiority of dimethyl-ether and its azeotropic refrigerant mixtures over the conventional refrigerant and hence, they can be considered as suitable alternative in domestic refrigerator.

\section{REFERENCES}

[1] Memet F. A performance analysis on a vapour compression refrigeration system generated by the replacement of R134a. Journal of Maritime Research 2014:11:83-87.

[2] Bolaji B. O. Experimental study of R152a to Replace R12 and R134a in a domestic refrigerator. Energy 2010:35(9):3793-3798. https://doi.org/10.1016/j.energy.2010.05.031

[3] Borokinni F. O., Bolaji B. O., Ismail A. A. Experimental analysis of the performance of the eco-friendly R510A and R600a refrigerants in a retrofitted vapour compression refrigerating system. International Journal of Maritime Science and Technology 2018:65:11-17. https://doi.org/10.17818/NM/2018/1.2

[4] Venkatarathnam G., Srinivasa M. S. Refrigerants for vapour compression refrigeration systems. Reson 2012:17:139162. https://doi.org/10.1007/s12045-012-0015-X

[5] Bhatkar V. W., Kriplani V. M., Awari G. K. Alternative refrigerants in vapour compression refrigeration cycle for sustainable environment: a review of recent research. International Journal of Environmental Science and Technology 2013:10:871-880. https://doi.org/10.1007/s13762-013-0202-7

[6] Bolaji B. O., Komolafe O. D., Ajayi F. O., Akinnibosun E. Performance assessment of three eco-friendly hydrofluorocarbon and hydrocarbon refrigerant mixtures as R22 alternatives in refrigeration system. Journal of Scientific Research 2015:23:1677-1684.

[7] Bolaji B. O., Huan Z. Ozone depletion and global warming: case for the use of natural refrigerant - a review. Renewable and Sustainable Energy Reviews 2013:18:49-54. https://doi.org/10.1016/j.rser.2012.10.008

[8] Daviran S., Kasaeian A., Golzari S., Mahian O., Nasirivatan S., Wongwises S. A comparative study on the performance of R1234yf and R134a as an alternative in automotive air conditioning systems. Applied Thermal Engineering 2017:110:1091-1100. https://doi.org/10.1016/j.applthermaleng.2016.09.034

[9] Bolaji B. O., Oyelaran O. A., Okoye O. C. Thermodynamic study of environment-friendly R429A, R435A and R457A refrigerants as substitutes for ozone depleting R22 in refrigeration and air-conditioning systems. Scientific Journal of Maritime Research 2017:31:45-52.

[10] Rhodes W. J. Stratospheric ozone protection: an EPA engineering perspective. Journal of the Air \& Waste Management Association 1991:41(12):1579-1584. https://doi.org/10.1080/10473289.1991.10466953 
[11] Bolaji B. O. Performance of a R22 split-air-conditioner when retrofitted with ozone friendly refrigerants (R410A and R417A). Journal of Energy in Southern African 2012:23(3):16-22. https://doi.org/10.17159/24133051/2012/v23i3a3168

[12] Fahey D. W. The Montreal Protocol protection of ozone and climate. Theoretical Inquiries in Law 2013:14:21-42. https://doi.org/10.1515/til-2013-004

[13] Banjo S. O., Bolaji B. O., Ajayi O. O., Olufemi B. P., Osagie I., Onokwai A. O. Performance enhancement using appropriate mass charge of R600a in a developed domestic refrigerator. International Conference on Energy and Sustainable Environment, IOP Conference Series: Earth and Environmental Science 2019:331:012025. https://doi.org/10.1088/1755-1315/331/1/012025

[14] Cleland D. J., Love R. J. Refrigerants - back to the future? Ecolibrium: Journal of the Australian Institute of Refrigeration. Air Conditioning and Heating 2012:32-39.

[15] Andersen S. O, Halberstadt M. L., Borgford-Parnell N. Stratospheric ozone, global warming, and the principle of unintended consequences - An ongoing science and policy success story. Journal of the Air \& Waste Management Association 2013:63(6):607-647. https://doi.org/10.1080/10962247.2013.791349

[16] Hurwitz M. M., Fleming E. L., Newman P. A., Li F., Mlawer E., Cady-Pereira K., Bailey R. Ozone depletion by hydrofluorocarbons. Geophysical Research Letters 2015:42:8686-8692. https://doi.org/10.1002/2015GL065856

[17] Fang X., Velders G. J., Ravishankara A. R., Molina M. J., Hu J., Prinn R. G. Hydrofluorocarbon (HFC) emissions in China: an inventory for 2005-2013 and projections to 2050. Environmental Science \& Technology 2016:50(4):20272034. https://doi.org/10.1021/acs.est.5b04376

[18] Calm J. M., Hourahan G. C. Physical, safety, and environmental data summary for current and alternative refrigerants. Proceedings for the $23^{\text {rd }}$ International Congress of Refrigeration. Prague, Czech Republic, August 2126, 2011.

[19] Bolaji B. O. Performance investigation of ozone-friendly R404A and R507 refrigerants as alternatives to R22 in a window air-conditioner. Energy and Buildings 2011:43(11):3139-3143. https://doi.org/10.1016/i.enbuild.2011.08.011

[20] Longo G. A., Righetti G., Zilio C. Heat-transfer assessment of the low GWP substitutes for traditional HFC refrigerants. International Journal of Heat and Mass Transfer 2019:139:31-38. https://doi.org/10.1016/j.ijheatmasstransfer.2019.04.144

[21] Aprea C., Greco A., Maiorino A. An experimental investigation on the substitution of R134a with R1234yf in a domestic refrigerator. Applied Thermal Engineering 2016:106:959-967. https://doi.org/10.1016/j.applthermaleng.2016.06.098

[22] UNEP. Report of the Refrigeration, Air-conditioning and Heat pumps Technical Options Committee, 2014 Assessment. United National Environment Programme, Nairobi, 2014.

[23] IPCC. Climate change: the scientific basis, in contribution of working group I to the IPCC fourth assessment report of the international panel on climate change. Cambridge University Press: Cambridge, 2007.

[24] Navarro-Esbri J., Mendoza-Miranda J. M., Mota-Babiloni A., Barraga-Cervera A., Barragan-Cervera A., Belman-Flores J. M. Experimental analysis of R1234yf as a drop-in replacement for R134a in a vapour compression system. International Journal of Refrigeration 2013:36(3):870-880. https://doi.org/10.1016/j.ijrefrig.2012.12.014

[25] Bolaji B. O. Influence of sub-cooling on the energy performance of two eco-friendly R22 alternative refrigerants. Journal of Science and Technology 2014:34(2):73-83. https://doi.org/10.4314/just.v34i2.9

[26] Zhang L., Zhao J. X., Yue L. F., Zhou H. X., Ren C. L. Cycle performance evaluation of various R134a/hydrocarbon blend refrigerants applied in vapour-compression heat pumps. Advances in Mechanical Engineering 2019:11:1-14. https://doi.org/10.1177/1687814018819561

[27] Banjo S. O., Bolaji B. O., Osagie I., Fayomi O. S. I., Fakehinde O. B., Olayiwola P. S., Oyedepo S. O., Udoye N. E. Experimental analysis of the performance characteristic of an eco-friendly HC600a as a retrofitting refrigerant in a thermal system. Journal of Physics: Conference Series 2019:1378:042033. https://doi.org/10.1088/1742$6596 / 1378 / 4 / 042033$

[28] Abas N., Kalair A. R., Khan N., Haider A., Saleem Z. and Saleem M. B. Natural and synthetic refrigerants, global warming: A review. Renewable and Sustainable Energy Reviews 2018:90:557-569. https://doi.org/10.1016/j.rser.2018.03.099

[29] Opeyemi L., Borokinni F., Adelani I., Olatunbosun B., Abdulkadir B. Effect of sub-cooling on the performance of a retrofitted domestic refrigerator using eco-friendly refrigerants. International Journal of Engineering Research and Technology 2017:6(4):670-679.

[30] Bolaji B. O., Abiala I. O., Ismaila S. O., Borokinni F. O. Theoretical comparison of two of eco-friendly refrigerants as alternative to R22 in using a simple vapour compression refrigeration system. Transactions of Famena 2014:38:59-70.

[31] Ohno Y., Yoshida M., Shikada T., Inokoshi O., Ogawa T., Inoue N. New direct synthesis technology for DME (dimethyl-ether) and its application technology. JFE Technical Report 2006:8:34-40.

[32] Afroz H. M. M., Miyara A. Binary mixtures of carbon dioxide and dimethyl-ether as alternative refrigerants and their vapour-liquid equilibrium data prediction. International Journal of Engineering, Science and Technology 2011:3:10 21. https://doi.org/10.4314/ijest.v3i1.67635 
[33] Sethi A., Becerra E. V., Motta S. Y. Low GWP R134a replacements for small refrigeration (plug-in) applications. International Journal of Refrigeration 2016:66:64-72. https://doi.org/10.1016/j.jirefrig.2016.02.005

[34] Bolaji B. O., Adeleke A. E., Adu M. R., Olanipekun M. U., Akinnibosun E. Theoretical investigation of energy-saving potential of eco-friendly R430A, R440A and R450A refrigerants in a domestic refrigerator. Iranian Journal of Science and Technology, Transactions of Mechanical Engineering 2019:43:103-112. https://doi.org/10.1007/s40997-017-0110-4

[35] He M-G., Song X-Z., Liu H., Zhang Y. Application of natural refrigerant propane and propane/isobutene in large capacity chest freezer. Applied Thermal Engineering 2014:70:732-736. https://doi.org/10.1016/j.applthermaleng.2014.05.097

[36] Yu C. C., Teng T-P. Retrofit assessment of refrigerator using hydrocarbon refrigerants. Applied Thermal Engineering 2014:66(1-2):507-518. https://doi.org/10.1016/j.applthermaleng.2014.02.050

[37] Sahoo K. C., Das S. N. Theoretical Design of adiabatic capillary tube of a domestic refrigerator using refrigerant R600a. American Journal of Engineering Research 2014:3:306-314.

[38] Dhananjeyan R., Senthil kumar S., Thilak M., Ganeshkarthikeyan M. Performance analysis of VCR system by using hydrocarbon refrigerants. International Journal of Innovative Research in Technology 2017:4:127-132.

[39] AIRAH. Flammable refrigerants - Safety guide. The Australian Institute of Refrigeration, Air Conditioning and Heating (AIRAH) 2013. [Online]. [Accessed: 18.03.2019]. Available: www.airah.org.au

[40] Choudhari C. S., Sapali S. N. Performance investigation of natural refrigerant R290 as a substitute to R22 in refrigeration systems. Energy Procedia 2017:109:346-352.

[41] Shaik S. V., Ashok-Babu T. P. S. Thermodynamic analysis of window air conditioner using sustainable refrigerant R290/RE170 and R1270/RE170 blends as substitutes to refrigerant R22. International Journal of Heat and Technology 2019:37:80-94.

[42] Bolaji B. O. Investigating the performance of some environment-friendly refrigerants as alternative to R12 in vapour compression refrigeration system. Ph.D. Thesis, Department of Mechanical Engineering, Federal University of Technology, Akure, Nigeria, 2008.

[43] Lemmon E. W., Huber M. L., McLinden M. O. Reference fluids thermodynamic and transport properties - REFPROP 9.1. National Institute of Standards and Technology (NIST), Gaithersburg (MD), Boulder, USA, 2013.

[44] Latini G., Sotte M. Thermal conductivity of refrigerants in the liquid state: A comparison of estimation methods. International Journal of Refrigeration 2012:35(5):1377-1383. https://doi.org/10.1016/j.ijrefrig.2012.04.009

[45] Di Nicola G., Pierantozzi M., Petrucci G., Stryjek R. Equation for the thermal conductivity of liquids and an artificial neural network. Journal of Thermophysics and Heat Transfer 2016:30(3):651-660. https://doi.org/10.2514/1.T4863

[46] Padilla M., Revellin R., Bonjour J. Exergy analysis of R413A as replacement of R12 in a domestic refrigeration system. Energy Conversion and Management 2010:51(11):2195-2201. https://doi.org/10.1016/j.enconman.2010.03.013

[47] Bolaji B. O., Adu M. R., Olanipekun M. U., Akinnibosun E. Energy Performance of Environmental-friendly R435A and R161 Refrigerants in Sub-cooling Refrigeration Systems. The Holistic Approach to Environment 2017:7(3):125137.

[48] Gil B., Fijałkowska B. Experimental Study of Nucleate Boiling of Flammable, Environmentally Friendly Refrigerants. Energies 2020:13(1):160. https://doi.org/10.3390/en13010160 